\title{
High-quality thermodynamic data on the stability changes of proteins upon single-site mutations
}

\author{
Fabrizio Pucci, ${ }^{*}$ Raphaël Bourgeas, ${ }^{\dagger}$ and Marianne Rooman ${ }^{\ddagger}$ \\ Department of BioModeling, BioInformatics $\&$ BioProcesses, \\ Université Libre de Bruxelles, CP 165/61, \\ Roosevelt Avenue 50, 1050 Brussels, Belgium
}

\begin{abstract}
We have set up and manually curated a dataset containing experimental information on the impact of amino acid substitutions in a protein on its thermal stability. It consists of a repository of experimentally measured melting temperatures $\left(T_{m}\right)$ and their changes upon point mutations $\left(\Delta T_{m}\right)$ for proteins having a well-resolved X-ray structure. This high-quality dataset is designed for being used for the training or benchmarking of in silico thermal stability prediction methods. It also reports other experimentally measured thermodynamic quantities when available, i.e. the folding enthalpy $(\Delta H)$ and heat capacity $\left(\Delta C_{P}\right)$ of the wild type proteins and their changes upon mutations $\left(\Delta \Delta H\right.$ and $\left.\Delta \Delta C_{P}\right)$, as well as the change in folding free energy $(\Delta \Delta G)$ at a reference temperature. These data are analyzed in view of improving our insights into the correlation between thermal and thermodynamic stabilities, the asymmetry between the number of stabilizing and destabilizing mutations, and the difference in stabilization potential of thermostable versus mesostable proteins.
\end{abstract}

\footnotetext{
*Electronic address: fapucci@ulb.ac.be

$\dagger$ Electronic address: rbourgeas@ulb.ac.be

${ }_{\ddagger}^{\ddagger}$ Electronic address: mrooman@ulb.ac. be
} 


\section{INTRODUCTION}

The availability of a complete and well-curated dataset for training and testing purposes is a basic prerequisite for the development of any knowledge-based bioinformatics prediction tool. Here we present a repository containing thermal and thermodynamic stability data on experimentally characterized single-site protein mutants for which an X-ray structure is available, which we have set up by screening the literature and freely accessible databases. This dataset is meant to be as complete as possible, and to contain as much as possible noise- and error-free data. The amount and quality of the data used to set up a predictor are indeed two fundamental requirements for getting reliable predictions.

We have used this dataset to design and test our method for predicting the change in melting temperature of proteins upon point mutations [1], and to compare its performance with that of other existing tools. This dataset is intended as a common benchmark for training and validating different in silico tools for protein stability prediction and rational design.

There is an increasing interest for the development of reliable stability predictors that can be used for rationally designing protein mutants with improved properties, and there is thus concomitantly an increasing need for high-quality and easily accessible datasets. Indeed, the design of new enzymes and other proteins that remain stable and active in unusual environments or at temperatures that differ from their physiological temperatures would allow the optimization of a wide series of biotechnological processes in many sectors such as agro-food, biopharmaceuticals and environment $[2,3]$.

Another asset of this dataset is that it can serve as a basis for large-scale analyses in view of improving our understanding of the factors that modulate the thermal resistance and other thermodynamic properties of proteins and their variation upon mutation. As a matter en fact, we performed in this paper some analyses that yield some interesting insights.

\section{BRIEF THEORETICAL REVIEW OF PROTEIN STABILITY}

The protein folding transition is thermodynamically characterized by a change in free energy, enthalpy, entropy and heat capacity. Assuming protein folding to be a two-state transition and the change in heat capacity $\Delta C_{p}$ to be temperature independent, the folding 
free energy $\Delta G(T)=G^{\text {folded }}(T)-G^{\text {unfolded }}(T)$ can be written as

$$
\Delta G(T)=\Delta H_{m}\left(1-\frac{T}{T_{m}}\right)-\Delta C_{p}\left(\left(T_{m}-T\right)+T \log \left[\frac{T}{T_{m}}\right]\right),
$$

where $T_{m}$ is the melting temperature and $\Delta H_{m}$ the enthalpic change measured at $T_{m}$. Note that with these conventions, $\Delta H_{m}$ and $\Delta C_{p}$ are negative; the folding free energy $\Delta G(T)$ is negative under physiological conditions and is positive for temperatures above $T_{m}$. The protein stability curve has thus an inverse bell shape, as shown in Figure 1.

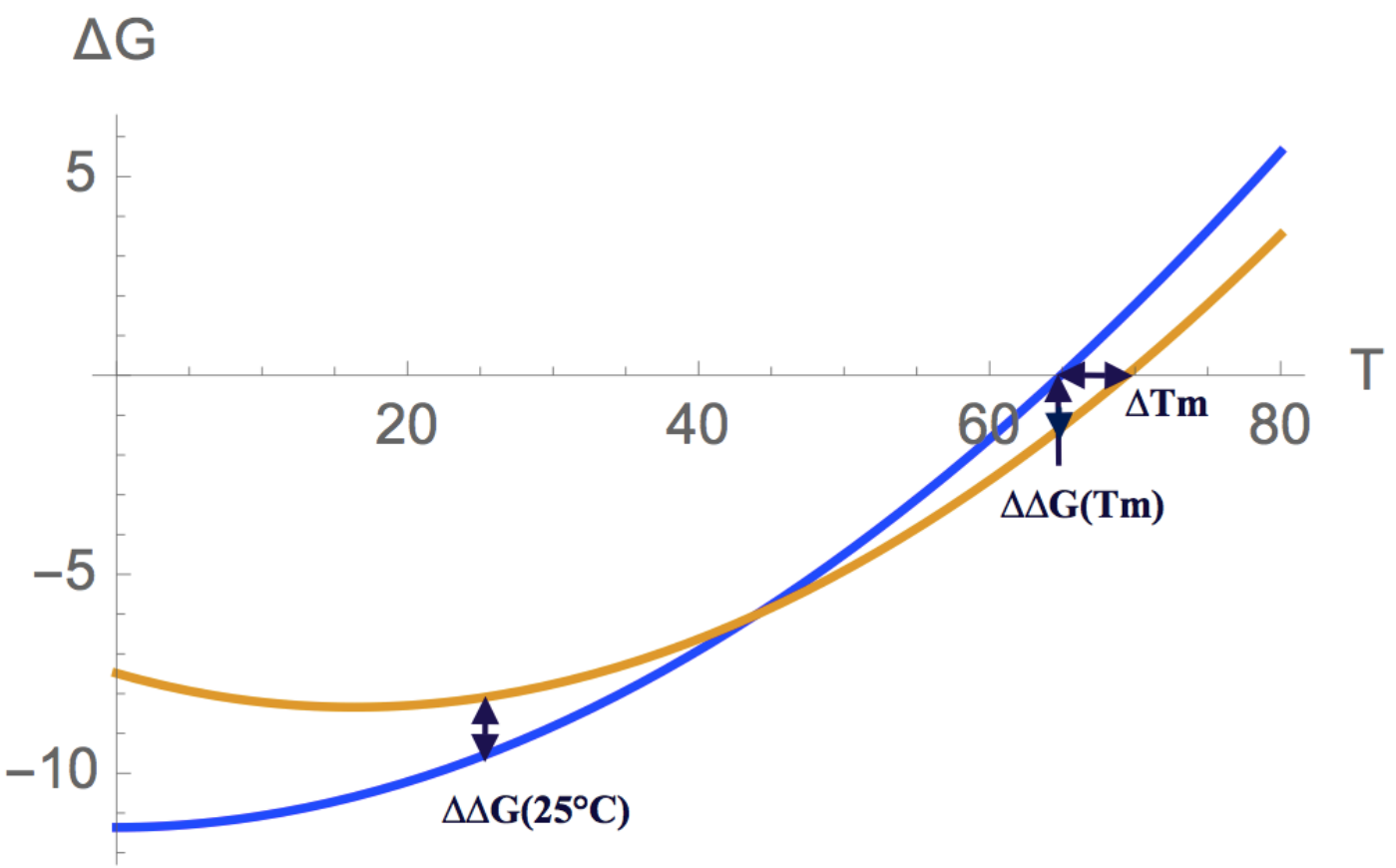

FIG. 1: Folding free energy in $\mathrm{kcal} / \mathrm{mol}$ as a function of the temperature for human lysozyme (PDB code 1LZ1) (blue curve) and its mutant R21A (green curve). While there is an anticorrelation between $\Delta T_{m}$ and $\Delta \Delta G\left(T_{r}\right)$ at $T_{r}=T_{m}$, there is a correlation between them at $T_{r}=25^{\circ} \mathrm{C}$. This is an example of mutation that thermally stabilizes the protein and thermodynamically destabilizes it.

When one or several residues of the wild type protein are substituted, the change in protein stability due to the mutation can be characterized by a temperature descriptor, namely the change in melting temperature upon mutation:

$$
\Delta T_{m}=T_{m}^{m u t}-T_{m}^{w i l d}
$$


which measures the change in thermal stability. It can also be characterized by a free energy descriptor, i.e. the change in folding free energy a the reference temperature $T_{r}$ (usually chosen to be the room temperature $\left.T_{r}=298 \mathrm{~K}\right)$ :

$$
\Delta \Delta G\left(T_{r}\right)=\Delta G^{\text {mut }}\left(T_{r}\right)-\Delta G^{\text {wild }}\left(T_{r}\right)
$$

which measures the change in so-called thermodynamic stability. Note that with these conventions, thermally stabilizing mutations have positive $\Delta T_{m}$-values, and thermodynamically stabilizing mutations have negative $\Delta \Delta G(298 K)$ values.

The dataset presented in this paper has been created in view of developing a predictor of protein thermal stability changes upon point mutations [1]. It thus contains all the point mutations with experimentally measured $\Delta T_{m}$ values that we have collected from the literature and satisfy certain criteria. The corresponding values of $\Delta \Delta G\left(T_{r}\right)$ and of the other thermodynamic quantities appearing in equation (1) are known only for a subset of the entries.

In order to understand the precise relation between thermal and thermodynamic stability changes, one needs to have independent experimental determinations of their respective descriptors $\Delta T_{m}$ and $\Delta \Delta G\left(T_{r}\right)$, or to know the values of all the thermodynamic quantities that appear in equation (1), i.e. $T_{m}, \Delta H_{m}$ and $\Delta C_{P}$, for both the wild type and mutant proteins. Unfortunately all these informations are not always available or not sufficiently accurately measured. Under the assumption that the mutated protein is a perturbation of the wild type, some approximations can be made; for example it is quite reasonable to consider that the parameter

$$
x=\frac{\Delta T_{m}}{T_{m}^{w i l d}}<<1,
$$

with the temperature expressed in Kelvin, is small and thus that an expansion of equation (3) in powers of $x$ can be performed. This yields:

$$
\begin{array}{r}
\Delta \Delta G\left(T_{r}\right)=\frac{\Delta H_{m} T_{r}}{\left(T_{m}^{\text {wild }}\right)^{2}} \Delta T_{m}+\Delta \Delta H_{m}\left[1-\frac{T_{r}}{T_{m}^{\text {wild }}}+\frac{T_{r}}{\left(T_{m}^{\text {wild }}\right)^{2}} \Delta T_{m}\right] \\
+\Delta \Delta C_{P}\left[T_{r}-T_{m}^{\text {wild }}-T_{r} \log \frac{T_{r}}{T_{m}^{\text {wild }}}\right]+\mathcal{O}\left[x^{2}\right]
\end{array}
$$


where $\Delta H_{m}=\Delta H^{\text {wild }}\left(T_{m}^{\text {wild }}\right), \Delta \Delta H_{m}=\Delta H^{\text {mut }}\left(T_{m}^{\text {wild }}\right)-\Delta H^{\text {wild }}\left(T_{m}^{\text {wild }}\right)$ and $\Delta \Delta C_{P}=$ $\Delta C_{P}^{m u t}-\Delta C_{P}^{\text {wild }}$. As seen from this equation, the correlation between $\Delta \Delta G\left(T_{r}\right)$ and $\Delta T_{m}$ generically depends on an intricate combination of variations of thermodynamic quantities. If we assume $\Delta \Delta H_{m} \simeq 0$ and $\Delta \Delta C_{p} \simeq 0$, equation (5) reduces to:

$$
\Delta \Delta G\left(T_{r}\right) \simeq \frac{\Delta H_{m} T_{r}}{\left(T_{m}^{\text {wild }}\right)^{2}} \Delta T_{m}
$$

Under this (strong) assumption, we find thus a linear relation between $\Delta \Delta G\left(T_{r}\right)$ and $\Delta T_{m}$; the proportionality coefficient is however protein-dependent. Note that $\Delta H_{m}$ is negative with our conventions, and that $\Delta \Delta G\left(T_{r}\right)$ and $\Delta T_{m}$ are thus anticorrelated.

On the other hand, at the reference temperature $T_{r}=T_{m}^{\text {wild }}$, equation (5) simplifies to:

$$
\Delta \Delta G\left(T_{m}\right)=\frac{\Delta H^{m u t}\left(T_{m}^{\text {wild }}\right)}{T_{m}^{\text {wild }}} \Delta T_{m}+\mathcal{O}\left[x^{2}\right]
$$

The proportionality assumption between $\Delta \Delta G(T)$ and $\Delta T_{m}$ is thus valid at $T_{m}$. If moreover we assume $\Delta \Delta H_{m} \simeq 0$, this equation becomes the Becktel-Schellman formula [4]:

$$
\Delta \Delta G\left(T_{m}\right) \simeq \Delta S_{m} \Delta T_{m}
$$

where $\Delta S_{m}=\Delta S^{\text {wild }}\left(T_{m}^{\text {wild }}\right)=\Delta H_{m} / T_{m}^{\text {wild }}$ is the entropic contribution at $T_{m}^{\text {wild }}$.

\section{METHODS}

\section{A. Dataset design}

We started collecting the mutations with experimentally measured $\Delta T_{m}$ values from the ProTherm database [5], and searched for additional entries by literature screening. Each entry (including those from ProTherm) was manually and carefully checked from the original literature to remove imprecisions and errors. We selected the mutations that satisfy the following criteria:

- Only single point mutations were included.

- Only mutations in proteins, whose three dimensional (3D) structures were experimentally solved by X-ray crystallography with a resolution of at most $2.5 \AA$, were considered. 
- Only mutations that were experimentally characterized in monomeric proteins were taken into account, irrespective of the oligomeric state of the biological unit; this ensures that the measured $T_{m}$ corresponds to the (un)folding transition and not to a change in quaternary state.

- Only wild-type and mutant proteins that are described in the reference articles as undergoing a two-state (un)folding transition were included.

- Destabilizing or stabilizing mutations by more than $20^{\circ} \mathrm{C}$ were overlooked, as they are likely to induce important structural modifications.

When several experimental $\Delta T_{m}$ values were found in the literature for the same mutation, we chose the one measured at $\mathrm{pH}$ closest to seven and with the lowest concentration of additives; if more than one measurement in the same conditions was available, the average $\Delta T_{m}$ was taken.

In addition to the change in melting temperature upon mutation, other thermodynamic quantities associated to the mutation are reported in the dataset when available. These are the $\Delta C_{P}$ of the wild type protein and its change upon mutation $\Delta \Delta C_{P}, \Delta \Delta G\left(T_{r}\right)$ and the reference temperature $T_{r}$ at which the measurement was performed, the $\Delta H_{m}$ of the wild type and

$$
\overline{\Delta \Delta} H_{m}=\Delta H_{m}^{m u t}\left(T_{m}^{m u t}\right)-\Delta H_{m}^{\text {wild }}\left(T_{m}^{\text {wild }}\right)=\Delta \Delta H_{m}+\Delta C_{P}^{m u t} \Delta T_{m}
$$

$\overline{\Delta \Delta} H_{m}$ refers to a quantity that is slightly different from $\Delta \Delta H_{m}$ appearing in equation (5): the former is computed at different $T_{m}$ values whereas the latter is computed at $T_{m}^{\text {wild }}$; the difference is proportional to $\Delta T_{m}$. We report in the dataset $\overline{\Delta \Delta} H_{m}$ rather than $\Delta \Delta H_{m}$ as these are the measured quantities. Note that for a given mutation these different quantities are not always measured in exactly the same experimentally conditions than the corresponding $\Delta T_{m}$ values.

When available, the $\Delta \Delta G^{\prime}$ 's indicated in the dataset are the values that are measured by monitoring the (un)folding transition through chemical (de)naturation using urea or guanidinium chloride $(\mathrm{GdmCl})$; the temperature at which the experiments were performed is also reported. If such data are not available but all the thermodynamic quantities in equation (1) are known for the wild type and the mutant proteins, they are used to evaluate $\Delta \Delta G$ at $25^{\circ} \mathrm{C}$. Otherwise, approximations were made to evaluate $\Delta \Delta G$, and the corresponding entries 
in the dataset are labeled by a subscript. The $\Delta \Delta G$ values obtained with the approximation consisting in considering $\Delta \Delta C_{P} \simeq 0$ are indicated with a subscript $(b)$; the temperature at which they were estimated is equal to $25^{\circ} \mathrm{C}$. When the stronger approximation consisting of supposing also $\Delta \Delta H_{m} \simeq 0$ (see equation (6)) is used to derive the value of $\Delta \Delta G$ from $\Delta T_{m}$, we mark it with the subscript $(a)$; the temperature at which this quantity is given is equal to $T_{m}^{\text {wild }}$. For the few entries whose values are labeled with a subscript $(c)$, the $\Delta \Delta G\left(25^{\circ} \mathrm{C}\right)$ values are computed from $\Delta T_{m}$ using an empirical correlation between the two quantities computed on a subset of mutants of the same wild type protein [6]. Finally the $\Delta \Delta G$ values at $T_{m}$ that are derived from the approximation (see ref. [7, 8]) $\Delta \Delta G\left(T_{m}\right)=$ $\frac{\left(\Delta H_{m}^{\text {wild }}+\Delta C_{P}^{\text {wild }} \Delta T_{m}\right) \Delta T_{m}}{T_{m}}$ are labeled with the subscript (d).

The experimental techniques used for measuring the protein melting temperatures and other thermodynamic quantities are indicated in the dataset. These are differential scanning calorimetry (DSC), circular dichroism (CD), absorbance (Abs), and fluorescence.

The Protein DataBank (PDB) code [9] of the best resolved 3D X-ray structure of each wild type protein is specified in the dataset. For a few entries, the PDB code is labeled with a subscript. This means that the wild type structure of the protein whose $\Delta T_{m}$ was measured was unavailable, and that the structure of an almost identical protein was used instead, under the assumption that the impact of the modification on the structure is negligible. In particular, the $\operatorname{lbni}_{h 102 a}$ code means that the structure is obtained from the PDB structure 1bni with the His residue at position 102 manually substituted into an Ala. The same procedure is used for the PDB structures $1 \mathrm{ycc}_{c 102 a}, 1 \operatorname{urp}_{l 265 c}$ and $5 \mathrm{pti}_{m 52 l}$. The other PDB codes with subscripts, i.e $1 \mathrm{tpk}, 1 \mathrm{yu} 5_{d 1}$ and $1 \mathrm{yu} 5_{d 2}$, refer to experimentally characterized proteins whose sequences have been manually truncated by a few residues compared to the original PDB structure. Note that we checked that the mutations or truncated residues in these pseudo-wild type proteins are all distant from the mutations whose $\Delta T_{m}$ was measured, so that they may be assumed as not interfering.

\section{B. Data records}

The dataset contains experimental information on 1,626 point mutations that have been introduced in about 93 proteins. This data was collected by screening the literature and databases, and carefully checked on the basis of the original articles. For each mutation, the 
following informations are reported:

- The PDB [9] code of the 3D structure of the wild type protein (Column II).

- The chain name, residue number and residue name of the wild type and mutant amino acids (Columns III-VI).

- The experimental value of the change in melting temperature upon mutation $\left(\Delta T_{m}\right)$ using the convention of equation (2) (Column VII).

- The experimentally measured melting temperature $\left(T_{m}\right)$ and the number of residues $\left(N_{r}\right)$ of the wild type protein (Columns VIII and XIV, respectively).

- The experimental values of $\overline{\Delta \Delta} H_{m}$, which is the change in calorimetric enthalpy upon mutation measured at the mutant and wild type melting temperatures, respectively, as defined in equation (9) (Column IX), and of the $\Delta H_{m}$ of the wild type protein at $T_{m}^{\text {wild }}$ (Column X), when available. The subscript $(e)$ means that the reported values correspond to the van't Hoff enthalpy instead of the calorimetric enthalpy.

- The experimentally measured values of $\Delta \Delta C_{P}$ (Column XI) and the $\Delta C_{P}^{\text {wild }}$ of the wild type protein (Column XII), when available.

- The values of $\Delta \Delta G\left(T_{r}\right)$, using the conventions of equation (3) (Column XIII), and the reference temperature $T_{r}$ (in degrees Celsius) at which they were measured or derived (Column XIV). Entries without superscripts are experimental or calculated from other measured thermodynamic quantities, whereas entries with superscripts (a), (b), (c) or (d) were obtained using different levels of approximations, as explained in the previous section.

- The resolution of the X-ray structure (in $\AA$ ) (Column XVI).

- The name of the protein and its host organism (Columns XVII-XVIII)

- The bibliographic references (Column XIX).

- The $\mathrm{pH}$ and the experimental technique used for measuring $\Delta T_{m}$ (Columns XX-XXI). 


\section{RESULTS}

We investigated some biophysical properties of the data reported in our dataset. First of all, the $\Delta T_{m}$ distribution obtained from all the entries is dominated by destabilizing mutations, as shown in Figure 2. The average $T_{m}$-value, $\left\langle\Delta T_{m}\right\rangle$, is indeed equal to $-2.7^{\circ} \mathrm{C}$, while the standard deviation and the kurtosis of the distribution are equal to $5.3^{\circ} \mathrm{C}$ and $4.0^{\circ} \mathrm{C}$, respectively. The large majority of point mutations (about 70\%) are thus destabilizing. Although this $\Delta T_{m}$ distribution is not built from the ensemble of possible mutations but rather from the subset of experimentally characterized mutations, we may nevertheless assume that it represents well the actual $\Delta T_{m}$ distribution of all possible mutations. The relative abundance of destabilizing mutations with respect to stabilizing ones can be interpreted as being due to the evolutionary force that tends to optimize the proteins for stability and thus to minimize the deleterious impact of random mutations. It must nevertheless be emphasized that all proteins are left with stability weaknesses [10] or frustrations [11], in particular in functional regions.

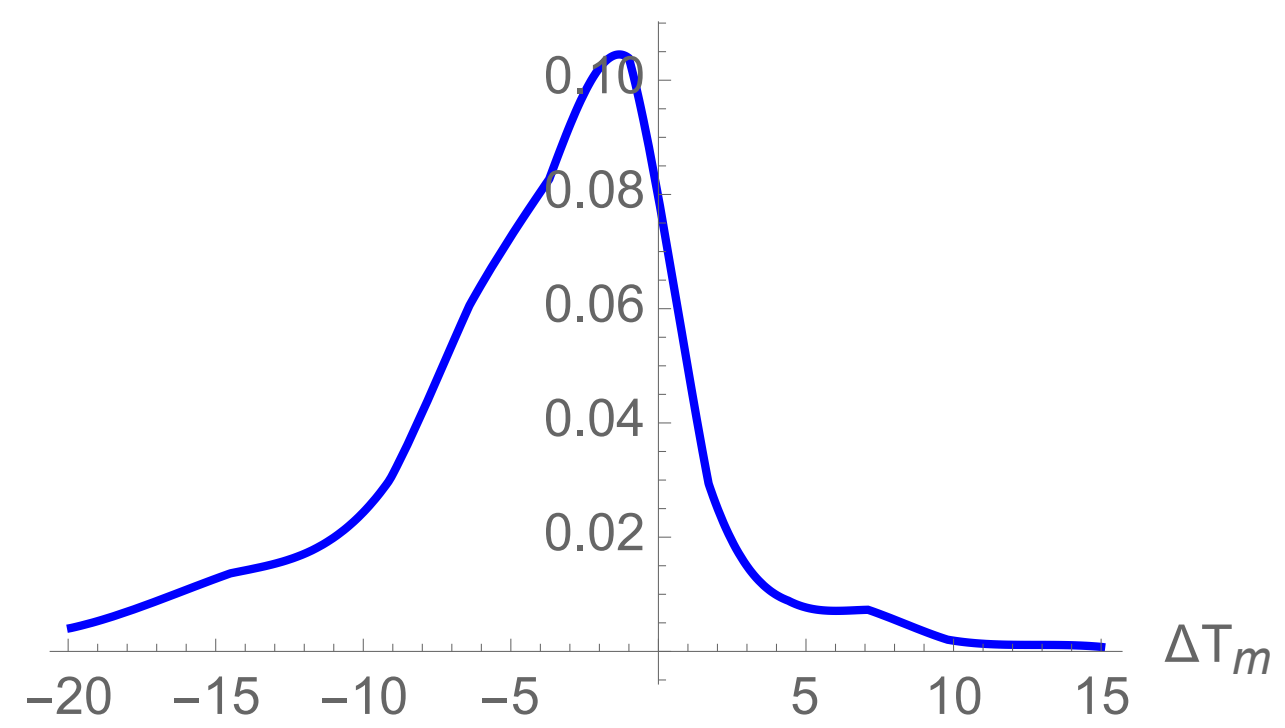

FIG. 2: Normalized $\Delta T_{m}$ distribution for the 1,626 mutations collected in the dataset.

The solvent accessibility of the mutated residues is an important feature that modulates the average stability changes. It is defined as the ratio between the solvent accessible surface of a residue $\mathrm{X}$ in a given structure and in the extended tripeptide Gly-X-Gly conformation, and has been computed using an in-house program [12]. In Figures 3a-c, we show the 
experimental $\Delta T_{m}$ distribution as a function of the solvent accessibility of the mutated residues; three solvent accessibility (Acc) ranges are considered: Acc $<15 \%$ (core), $15 \%<$ Acc $<50 \%$ (partially buried) and Acc $>50 \%$ (surface). The three distributions were found to be significantly different according to the 2-sample Kolmogorov-Smirnov (K-S) test (Pvalue $\left.<10^{-3}\right)$. The mean $\left\langle\Delta T_{m}\right\rangle$ values of the distributions are equal to $-4.3^{\circ} \mathrm{C},-1.6^{\circ} \mathrm{C}$ and $-1.1^{\circ} \mathrm{C}$ for the core, partially buried and surface mutations, respectively. As expected, the mutations in the core are on the average more destabilizing than those at the surface since core residues play a stronger role in the structural stability than surface residues, which also contribute to stability but to a lesser extent.
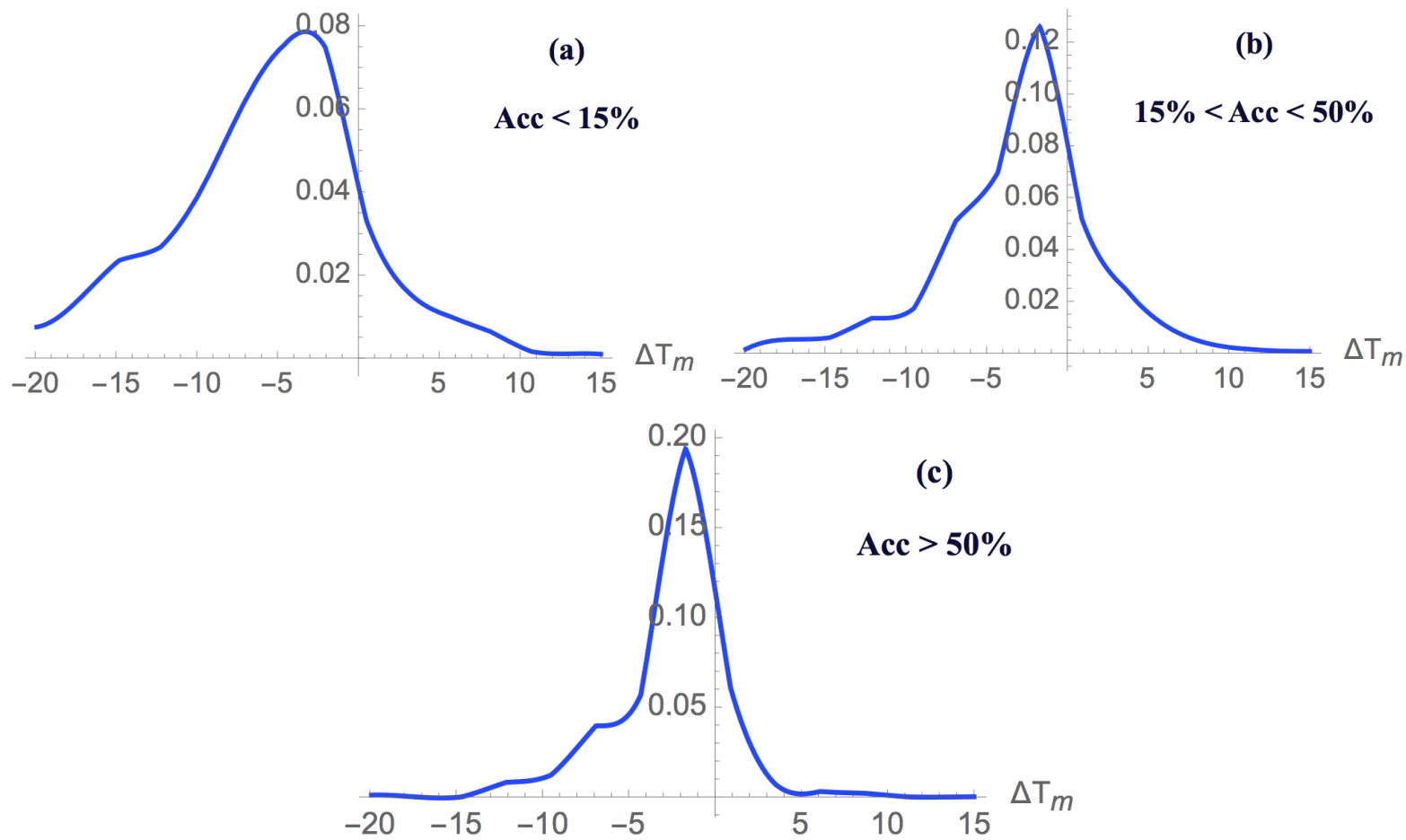

FIG. 3: Normalized $\Delta T_{m}$ distribution for : (a) 734 mutations in the protein core (Acc $<15 \%$ ), (b) 513 mutations of partially buried residues $(15 \%<$ Acc $<50 \%)$ and (c) 379 mutations at the protein surface $($ Acc $>50 \%)$

It is also informative to analyze the relation between $\Delta T_{m}$ and $T_{m}$. Indeed, it could be argued that it is "easier" to destabilize thermostable proteins or equivalently, to stabilize mesostable proteins. To check this hypothesis, we computed $\left\langle\Delta T_{m}\right\rangle$ separately for the mu- 
tations introduced in thermostable proteins defined here as having a melting temperature higher than $65^{\circ} \mathrm{C}$ and those introduced in mesostable proteins with $T_{m}<65^{\circ} \mathrm{C}$. We obtain a value of $\left\langle\Delta T_{m}\right\rangle=-3.6^{\circ} \mathrm{C}$ for thermostable proteins and $\left\langle\Delta T_{m}\right\rangle=-2.1^{\circ} \mathrm{C}$ for mesostable proteins. On the average, mutations in thermostable proteins are thus more destabilizing than in mesostable proteins. Moreover, the normalized $\Delta T_{m}$ distributions for mesostable and thermostable proteins are shown in Figure 4. They are statistically different according to the K-S test with a $\mathrm{P}$-value $<10^{-4}$, and the former appears to be shifted towards stabilizing mutations compared to the latter. This interesting result supports the view that the fraction of stabilizing mutations is larger in mesostable proteins than in thermostable proteins, and thus that the former are easier to stabilize than the latter, in agreement with the starting hypothesis.

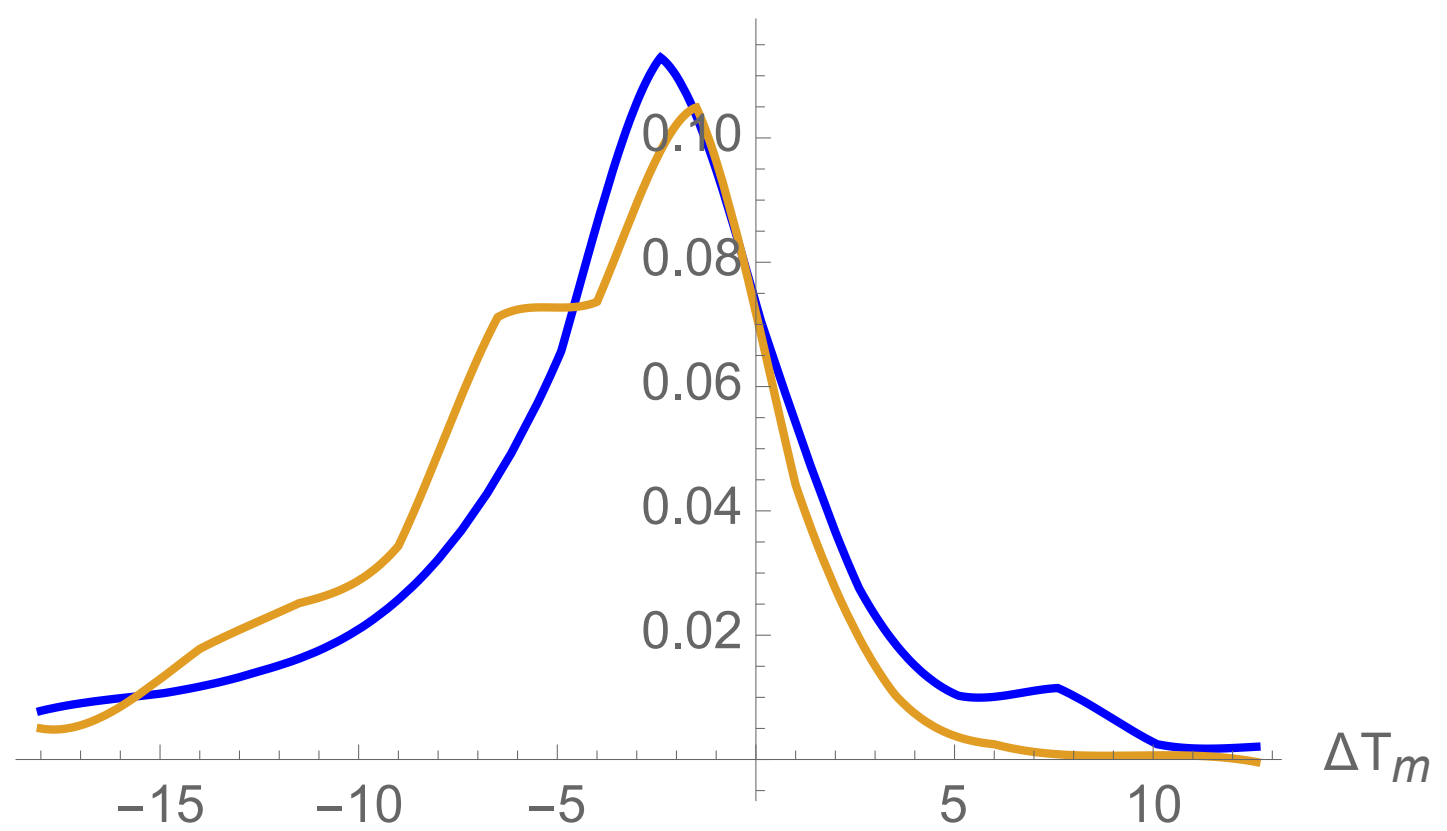

FIG. 4: Normalized $\Delta T_{m}$ distributions for mesostable (blue) and thermostable proteins (orange).

We also analyzed the other thermodynamic quantities reported in our dataset and first of all, the change in folding enthalpy upon point mutations. The normalized $\overline{\Delta \Delta} H_{m}$ distribution (see equation (9)) is plotted in Figure 5a; its mean value is $\left\langle\overline{\Delta \Delta} H_{m}\right\rangle=7.3$ $\mathrm{kcal} / \mathrm{mol}$ for the set of 993 entries for which this quantity has been measured experimentally. Hence, the mutations are on the average enthalpically destabilizing at $T_{m}$. Figure $5 \mathrm{~b}$ shows the normalized distribution of the change in entropy upon mutation 
$\overline{\Delta \Delta} S_{m}=\Delta S^{\text {mut }}\left(T_{m}^{\text {mut }}\right)-\Delta S^{\text {wild }}\left(T_{m}^{\text {wild }}\right)$. The mean value of the distribution is found to be $\left\langle\overline{\Delta \Delta} S_{m}\right\rangle=0.04 \mathrm{kcal} /(\mathrm{mol} \mathrm{K})$.

Finally, we plotted the normalized distribution of $\Delta \Delta C_{P}$ and $\Delta \Delta G$ in Figures $5 \mathrm{c}$-d. The mean values of these two distributions are positive: $\left\langle\Delta \Delta C_{p}\right\rangle=0.08 \mathrm{kcal} /(\mathrm{mol} \mathrm{K})$ for the set of 250 entries for which this value has been measured, and $\langle\Delta \Delta G\rangle=0.89 \mathrm{kcal} / \mathrm{mol}$ for 1,147 entries. Hence, the majority of mutant proteins have a less negative $\Delta C_{P}$ and a less negative $\Delta G$ than wild type proteins; the mutant proteins are thus on the average less thermodynamically stable than the wild type. Note that the asymmetric nature of the $\Delta \Delta G$ distribution is likely to cause biases in the prediction methods that use these data as learning set [13].

In summary, the large majority of the mutations are thermodynamically destabilizing (as measured by positive $\Delta \Delta G$ ) and thermally destabilizing (as measured by negative $\Delta T_{m}$ ).
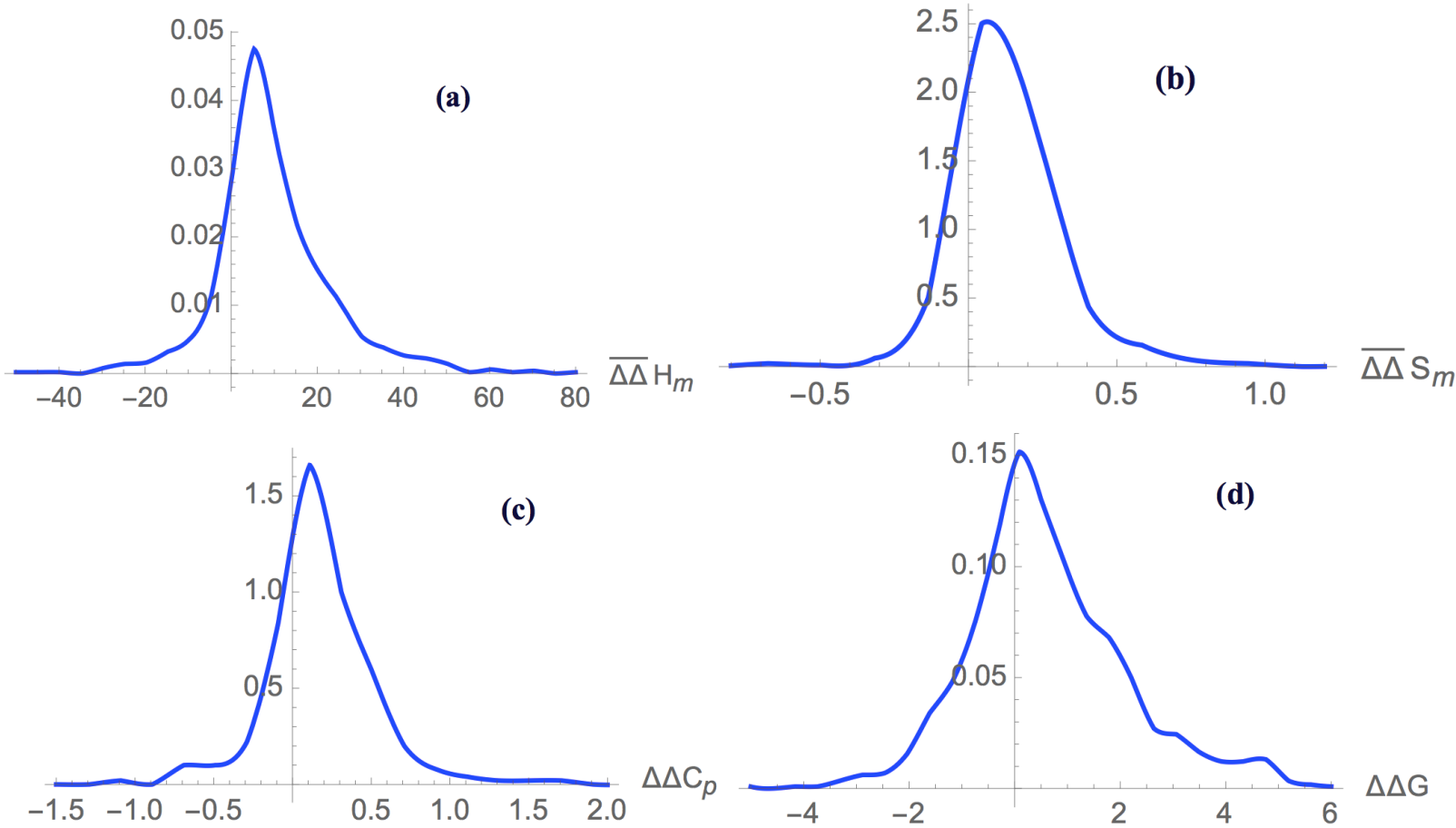

FIG. 5: Normalized distributions for : (a) $\overline{\Delta \Delta} H_{m}$ (in kcal $/ \mathrm{mol}$ ) and (b) $\overline{\Delta \Delta} S_{m}$ (in kcal/(mol K)) obtained from 993 mutations, (c) $\Delta \Delta C_{p}$ (in kcal/(mol K)) obtained from 250 mutations, and (d) $\Delta \Delta G$ (in kcal/mol) obtained from 1,147 mutations.

The next point we investigated is the correlation between the thermodynamic stability descriptor $\Delta \Delta G\left(T_{r}\right)$ and the thermal stability descriptor $\Delta T_{m}$. Indeed, these two quantities 
are often taken as equivalent stability measures even though this assumption is based on an approximation, as shown in equation (6). Nevertheless, this hypothesis seems a priori not totally unjustified, as the linear anticorrelation between the two quantities is in general quite good. In our dataset, the Pearson correlation coefficient $r$, computed on the 1,147 mutations for which both $\Delta \Delta G\left(T_{r}\right)$ and $\Delta T_{m}$ are available independently from the choice of $T_{r}$ is equal to:

$$
r_{\left[\Delta \Delta G\left(T_{r}\right), \Delta T_{m}\right]}=-0.82 .
$$

We must however notice that the temperature at which the $\Delta \Delta G$ measurements were performed is not always the same (as described in the "Dataset design" subsection of Methods); it is usually either $25^{\circ} \mathrm{C}$ or the $T_{m}$ of the wild type protein.

For the subset of 461 mutations for which $\Delta \Delta G$ has been measured or computed at $T_{m}^{\text {wild }}$, the linear anti-correlation is close to perfect:

$$
r_{\left[\Delta \Delta G\left(T_{m}\right), \Delta T_{m}\right]}=-0.94
$$

The anticorrelation does not reach -1 since the proportionality coefficient between $\Delta \Delta G\left(T_{m}\right)$ and $\Delta T_{m}$ is protein-dependent (see equations (6)-(7)). It is illustrated in Figure 6b.

In contrast, for the 449 mutations for which $\Delta \Delta G\left(25^{\circ} \mathrm{C}\right)$ has been directly measured or for which all thermodynamic quantities that allow using the full equation (5) have been measured (entries without subscript in the dataset), the anticorrelation is much lower:

$$
r_{\left[\Delta \Delta G\left(25^{\circ} \mathrm{C}\right), \Delta T_{m}\right]}=-0.68
$$

as shown in Figure 6a. We would like to stress the value of this $\Delta \Delta G\left(25^{\circ} \mathrm{C}\right)-\Delta T_{m}$ anticorrelation coefficient can be expected to be close to the real one, as it has not been artificially improved by adding computed $\Delta \Delta G^{\prime}$ 's that presuppose this anticorrelation.

For some entries, the two descriptors $\Delta \Delta G\left(25^{\circ} \mathrm{C}\right)$ and $\Delta T_{m}$ are correlated rather than anticorrelated. These signal interesting mutations that stabilize the protein thermally while destabilizing it thermodynamically at room temperature, or conversely, destabilize it thermally while stabilizing it thermodynamically. As an example of such an unusual behavior, we plotted in Figure 1 the full protein stability curve of the wild type human lysozyme and of the mutant R21A [14]; these are one of the entries of our dataset. 

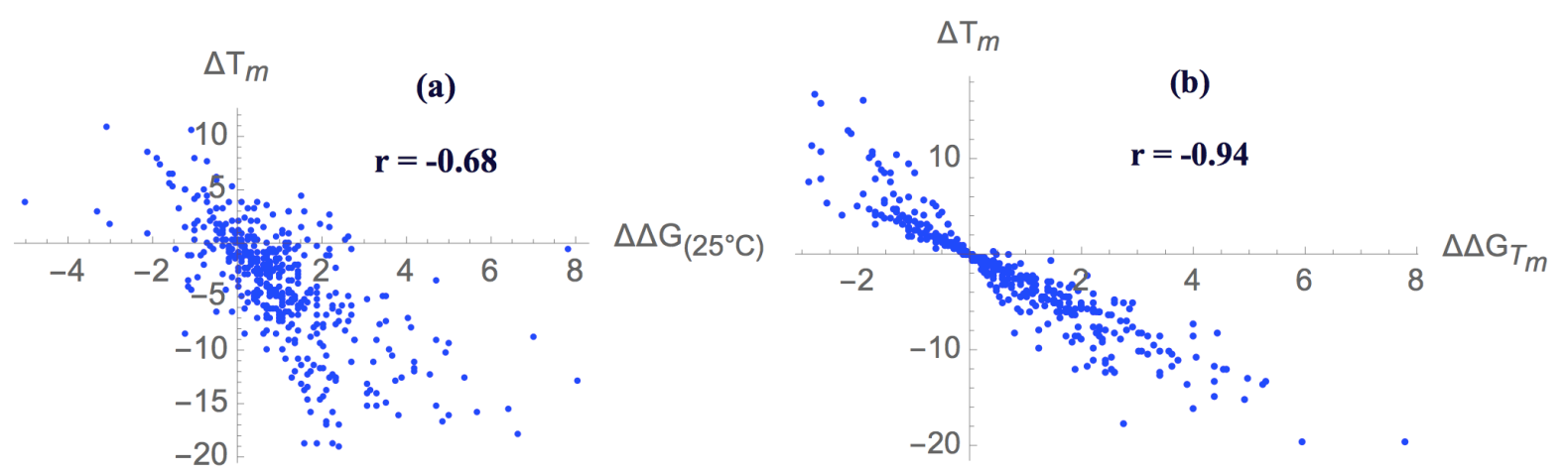

FIG. 6: Anticorrelation between the two descriptors of protein stability. (a) Anticorrelation between $\Delta T_{m}$ and $\Delta \Delta G\left(25^{\circ} \mathrm{C}\right)$ and (b) anticorrelation between $\Delta T_{m}$ and $\Delta \Delta G\left(T_{m}\right)$ where $T_{m}$ is the melting temperature of the wild type protein.

\section{Sources of experimental errors}

The experimental errors on the measured thermodynamic quantities describing the folding transition have to be taken in consideration. The most noisy thermodynamic quantities are $\Delta C_{P}$. Their error is generally of the order of $10-20 \%$. Sometimes it is of the same order as $\Delta \Delta C_{P}$ itself, which makes the numeric evaluation of equation (5) not quite precise, even though the $\Delta \Delta C_{P}$ term is subleading compared to the others.

The errors on the two thermodynamic descriptors $\Delta H_{m}$ and $T_{m}$ are in general less severe, being of the order of a few percents. These should thus not really affect the results obtained in this analysis.

Another source of error comes from the fact that the experiments are often performed in different environmental conditions in terms of $\mathrm{pH}$, buffer type, ionic concentration and additives. Such errors are non negligible, even if their effect can be expected to be less important for the variation of the thermal characteristics upon mutations compared to that of the thermal characteristics themselves. Moreover, to decrease this effect, we have collected data that are as much as possible uniform in terms of environmental variables, as explained in the section "Dataset design". Note that the size of this type of error is difficult to quantify in general. 


\section{Usage notes}

The dataset that we have constructed is available as a pdf file in attachment to this paper and can be downloaded as a text file at the address http://babylone.ulb.ac.be.

\section{Acknowledgments}

We acknowledge support from an FRFC grant from the Belgian Fund for Scientific Research (FNRS). RB is a Postdoctoral Fellow, FP a Postdoctoral Researcher and MR a Research Director at the FNRS.

[1] Pucci, F., Bourgeas, R., \& Rooman, M. Predicting protein thermal stability changes upon point mutations using statistical potentials: Introducing HoTMuSiC, submitted (2015).

[2] Haki, G.D. \& Rakshit, S.K., Developments in industrially important thermostable enzymes: a review. Bioresour Technol 89, 17-34 (2003).

[3] Cruins, M.E., Janssen, A.E. \& Boom, R.M., Thermozymes and their applications. Appl Biochem Biotechnol 90, 155-186 (2001).

[4] Becktel, W. J. \& Schellman, J. A. Protein stability curves. Biopolymers 26, 1859-1877 (1987).

[5] Kumar, M.D.S. et al., ProTherm and ProNIT: thermodynamic databases for proteins and protein-nucleic acid interactions. Nucl. Acids Res. 34, D204-D206 (2006).

[6] Di Nardo, A.A, Larson, S.M. \& Davison, A.R., The relationship between conservation, thermodynamic stability, and function in the SH3 domain hydrophobic core. J. Mol. Biol. 333, 641-655 (2003).

[7] Pinker, R.J., Lin, L., Rose, G.F.\& Kallenbach, N.R., Effects of alanine substitutions in alpha-helices of sperm whale myoglobin on protein stability. Protein Science, 2, 1099-1105 (1993)

[8] Lin, L., Pinker, R.J. , \& Kallenbach, N.R., Alpha-helix stability and the native state of myoglobin. Protein Science, 2, 1099-1105 (1993).

[9] Berman, H. M. et al., The Protein Data Bank. Nucl. Acids Res. 28, 235-242 (2000).

[10] De Laet, M., Gilis, D. \& Rooman, M. Stability strengths and weaknesses in protein structures 
detected by statistical potentials. Application to bovine seminal ribonuclease. Proteins Epub ahead of print (2015).

[11] Bryngelson, J. D. \& Wolynes, P. G., Spin glasses and the statistical mechanics of protein folding. Proc Natl Acad Sci USA 84, 7524-7528 (1987).

[12] Dalkas, A. D, Teheux, F., Kwasigroch, J. M. \& Rooman, M. Cation- $\pi$, amino- $\pi, \pi-\pi$, and H-bond interactions stabilize antigen-antibody interfaces. Proteins 82, 1734-1746 (2014).

[13] Pucci, F., Bernaerts, K., Teheux, F., Gilis, D. \& Rooman, M. Symmetry principles in optimization problems : an application to protein stability prediction. IFAC-PapersOnLine 48, 458-463 (2015).

[14] Schubert, W.D. et al., X-ray crystallographic and calorimetric studies of the effects of the mutation Trp59-> Tyr in ribonuclease T1. Eur. J. Biochem. 220, 527-534 (1994).

\section{Data Citations}

Bibliographic information for the data records described in the manuscript.

1. Spuergin, P., Abele, U. \& Schulz, G.E. Eur. J. Biochem., 231, 405-413 (1995).

2. Evrard C., Fastrez J. \& Soumillion P., FEBS Lett., 460, 442-446 (1999).

3. Rose T. et al., J. Biol. Chem., 266, 23654-23659 (1991).

4. Reinstein J. et al., J. Biol. Chem., 264, 8107-8112 (1989).

5. D'Amico S., Gerday C. \& Feller G., J. Biol. Chem., 276, 25791-25796 (2001).

6. Vogl T, Jatzke C, Hinz HJ, Benz J \& Huber R, Biochemistry, 36, 1657-1668 (1997).

7. Hannemann F. et al., Biochemistry, 41, 11008-11016 (2002).

8. Burova T.V. et al., Protein Science, 5, 1890-1897 (1996).

9. Bedell J.L., Edmondson S.P. \& Shriver J.W., Biochemistry, 44, 915-925 (2005).

10. Clark A.T. et al., Biochemistry, 43, 2840-2853 (2004).

11. Catanzano F. et al., Biochemistry, 37, 10493-10498 (1998).

12. Clark A.T. et al., Biochemistry, 43, 2840-2853 (2004).

13. Vu N.D., Feng H. \& Bai Y. Biochemistry, 43, 3346-3356 (2004).

14. Matouschek A. et al., Protein Eng., 7, 1089-1095 (1994).

15. Axe D.D., Foster N.W. \& Fersht A.R., J. Mol. Biol., 286, 1471-1485 (1999).

16. Kellis J.T., Nyberg K. \& Fersht A.R., Biochemistry, 28, 4914-4922 (1989). 
17. Pinker R.J. et al., Protein Science, 2, 1099-1105 (1993).

18. Lin L., Pinker R.J. \& Kallenbach N.R., Biochemistry, 32, 12638-12643 (1993).

19. Perl D. \& Schmid F.X., J. Mol. Biol., 313, 343-357 (2001).

20. Wunderlich M. \& Schmid F.X., Protein Eng., 19, 355-358 (2006).

21. Wunderlich M., Martin A. \& Schmid F.X., J. Mol. Biol., 347, 1063-1076 (2005).

22. Gribenko A.V. \& Makhatadze G.I., J. Mol. Biol., 366, 842-856 (2007).

23. Schindler T. et al., Proteins, 30, 401-406 (1998).

24. Yao P. et al., Protein Eng., 10, 575-581 (1997).

25. Wang Z.Q. et al., Biophys. Chem., 83, 3-17 (2000).

26. Xue L.L. et al., Biochemistry, 38, 11961-11972 (1999).

27. Roberge M. et al., Protein Eng., 12, 251-257 (1999).

28. Benito A .et al., Protein Eng., 15, 887-893 (2002).

29. Tigerstrom A. et al., Biochemistry, 43, 12563-12574 (2004).

30. Cavallin A. et al., J. Biol. Chem., 275, 1665-1672 (2000).

31. Carra J.H. \& Privalov P.L., Biochemistry, 34, 2034-2041 (1995).

32. Byrne M.P. \& Stites W.E., Biophys. Chem., 125, 490-496 (2007).

33. Alexandrescu A.T., Hinck A.P. \& Markley J.L., Biochemistry, 19, 4516-4525 (1990).

34. Chen J. et al., J. Mol. Biol., 303, 125-130 (2000).

35. Tanaka A., Flanagan J. \& Sturtevant J.M., Protein Science, 2, 567-576 (1993).

36. Byrne M.P. \& Stites W.E., Protein Science, 4, 2545-2558 (1995).

37. Spencer D.S. \& Stites W.E.,J. Mol. Biol., 257, 497-499 (1996).

38. Carra J.H., Anderson E.A. \& Privalov P.L., Protein Science, 3, 952-959 (1994).

39. Leung K.W. et al., J. Biol. Chem., 276, 46039-46045 (2001).

40. Eftink M.R. et al., Biochemistry, 30, 1193-1199 (1991).

41. Hirano S. et al., Proteins, 58, 271-277 (2005).

42. Koide A. et al., Biochemistry, 40, 10326-10333 (2001).

43. Moutiez M. et al., Protein Science, 8, 106-112 (1999).

44. Morii H. et al., J. Mol. Biol., 292, 909-920 (1999).

45. Lee C.F. et al., J. Biol. Chem., 48, 419-431 (2005).

46. Lee C.F., Makhatadze G.I. \& Wong KB, Biochemistry, 44, 16817-16825 (2005).

47. Sandgren M. et al., Protein Science, 12, 848-860 (2003). 
48. Sandgren M. et al., Protein Science, 12, 2782-2793 (2003).

49. Greene L.H. et al., Protein Eng., 12, 581-587 (1999).

50. Vanhooren A. et al., Proteins, 60, 118-130 (2005).

51. Oroguchi T. et al.,J. Mol. Biol., 354, 164-172 (2005).

52. Merz A. et al., J. Mol. Biol., 288, 753-763 (1999).

53. Venkataramani R.N. et al.,J. Biol. Chem., 277, 48827-48833 (2002).

54. Mukaiyama A. et al.,Biochemistry, 45, 12673-12679 (2006).

55. Dong H.A. et al.,J. Mol. Biol., 378, 264-272 (2008).

56. LeMaster D. \& Hernandez G., Biophysical Chemistry, 125, 483-489 (2007).

57. Gray R.D. \& Trent J.O., Biochemistry, 44, 2469-2477 (2005).

58. Nikolopoulos G. et al., Biochim et Bioph Acta, 1774, 772-780 (2007).

59. Beadle B.M. et al., Protein Science, 8, 1816-1824 (1999).

60. Mavromatis K. et al., Protein Eng., 16, 497-503 (2003).

61. Gassner N.C. et al., Biochemistry, 38, 14451-14460 (1999).

62. Xu J. et al., Protein Science, 7, 158-177 (1998).

63. Lipscomb L.A. et al., Protein Science, 7, 765-773 (1998).

64. Eriksson A.E., Baase W.A.\& Matthews B.W., J. Mol. Biol, 229, 747-769 (1993).

65. Wray J.W. et al., J. Mol. Biol., 292, 1111-1120 (1999).

66. Blaber M. et al., J. Mol. Biol., 246, 317-330 (1999).

67. Xu J. et al., Protein Science, 10, 1067-1078 (2001).

68. Daopin S. et al., J. Mol. Biol., 221, 647-667 (1991).

69. Mooers B.H. et al., J. Mol. Biol., 332,741-756 (2003).

70. Blaber M. et al., Biochemistry, 32, 11363-11373 (1993).

71. Shoichet B.K. et al., Proc. Natl. Acad. Sci. USA, 92, 452-456 (1995).

72. Blaber M. et al., J. Mol. Biol., 235, 600-624 (1994).

73. Pjura P. et al., Protein Science, 2, 2217-2225 (1993).

74. He M.M. et al., Protein Science, 13, 2716-2724 (2004).

75. Anderson D.E., Becktel W.J. \& Dahlquist F.W., Biochemistry, 29, 2403-2408 (1990).

76. Nicholson H. et al., Biochemistry, 30, 9816-9828 (1991).

77. Bell J.A. et al., Biochemistry, 31, 3590-2596 (1992).

78. Heinz D.W., Baase W.A. \& Matthews B.W., Proc. Natl. Acad. Sci. USA, 89, 3751-3755 
(1992).

79. Lu J. et al., Biochemistry, 31, 7765-7772 (1992).

80. Sauer U.H., Daopin S., Matthews B.W., J. Biol. Chem., 267, 2393-2399 (1992).

81. Liu R., Baase W.A. \& Matthews B.W., J. Mol. Biol., 295, 127-145 (2000).

82. Hurley J.H., Baase W.A. \& Matthews B.W., J. Mol. Biol., 224, 1143-1159 (1992).

83. Anderson DE al., Protein Science, 2, 1285-1290 (1993).

84. Eriksson A.E. et al. Science, 255, 178-183 (1992).

85. Daopin S. et al., Biochemistry, 30, 11521-11529 (1991).

86. Gassner N.C., Baase W.A. \& Matthews B.W., Proc. Natl. Acad. Sci. USA, 93, 12155-12!58 (1996).

87. Takano K., Yamagata Y. \& Yutani K, J. Mol. Biol., 280, 749-761(1998).

88. Takano K., Yamagata Y. \& Yutani K, Protein Eng., 16, 5-9 (1998).

89. Takano K. et al., J. Biol. Chem., 278, 31790-31795 (2003).

90. Grimsley G.R. et al., Protein Science, 8, 1843-1849 (1999).

91. Trevino S.R. et al., J. Mol. Biol., 354, 967-978 (2005).

92. Yakolev G.I. et al., Protein Science, 12, 2367-2373 (2003).

93. Herbert E.J. et al., Biochemistry, 37, 16192-16200 (1998).

94. Takano K. et al., Eur. J. Biochem., 266, 675-682 (1999).

95. Funahashi J. et al., J. Biol. Chem., 277, 21792-21800 (2002).

96. Funahashi J. et al., Biochemistry, 39, 14448-14456 (2000).

97. Takano K. et al., Biochemistry, 36, 688-698 (1997).

98. Takano K. et al., Biochemistry, 39, 12375-12381 (2000).

99. Takano K., Yamagata Y. \& Yutani K., Biochemistry, 40, 4853-4858 (2001).

100. Takano K. et al., Proteins, 45, 274-280 (2001).

101. Yamagata Y. et al., Biochemistry, 37, 9355-9362 (1998).

102. Takano K. et al., Proteins, 44, 233-243 (2001).

103. Takano K. et al., Biochemistry, 38, 6623-6629 (1999).

104. Takano K., Yamagata Y., Yutani K., Biochemistry, 39, 8655-8665 (2000).

105. Takano K .et al., Biochemistry, 38, 12698-12708 (1999).

106. Takano K. et al., J. Mol. Biol., 274, 132-142 (1997).

107. Takano K. et al., Protein Eng., 12, 663-672 (1999). 
108. Herning T. et al., Biochemistry, 31, 7077-7085 (1992).

109. Funahashi J. et al., Protein Eng., 12, 841-850 (1999).

110. Vu D.M. et al., Protein Science, 10, 2028-2036 (2001).

111. Notomista E. et al., Biochemistry, 39, 8711-8718 (2000).

112. Arnold U. et al., Biochemistry, 45, 3580-3587 (2006).

113. Choi E.J. \& Mayo S.L., Protein Eng, Des, Sel, 19, 285-289 (2006).

114. Merkel J.S., Sturtevant J.M. \& Regan L., Structure, 7, 1333-1343 (1999).

115. Nicholson E.M., Peterson R.W. \& Scholtz J.M., J. Mol. Biol., 321, 355-362 (2002).

116. Cabrita L.D., Whisstock J.C. \& Bottomley S.P., Biochemistry, 41, 4575-4581 (2002).

117. Tew J.D. \& Bottomley S.P., J. Mol. Biol., 313, 1161-1169 (2001).

118. Gilis D. et al., J. Mol. Biol., 325, 581-589 (2003).

119. Greene L.H. et al., Protein Science, 10, 2301-2306 (2001).

120. De Vos S. et al., Biochemistry, 40, 10140-10149 (2001).

121. Schubert W.D. et al., Eur. J. Biochem., 220, 527-534 (1994).

122. Giletto A. \& Pace C.N., Biochemistry, 38, 13379-13384 (1999).

123. Shirley B.A. et al., J. Biol. Chem., 264, 11621-11625 (1989).

124. Herbet E.J. et al., Biochemistry, 37, 16192-16200 (1998).

125. Grimsley G.R. et al., Protein Science, 8, 1843-1849 (1998).

126. Agah S., Larson J.D. \& Henzl M.T., Biochemistry, 42, 10886-10895 (2003).

127. Navon A. et al., Biochemistry, 40, 93-104 (2001).

128. Gotte G. et al., Biochemistry, 45, 10795-10806 (2006).

129. Chatani E. et al., Biochemistry, 41, 4567-4574 (2002).

130. Kadonosono T. et al., Biochemistry, 42, 10651-10658 (2003).

131. Dodge R.W. \& Scheraga H.A., Biochemistry, 35, 1548-1559 (1996).

132. Font J. et al., Biol. Chem. Hoppe-Seyler, 387, 285-296 (2006).

133. Catanzano F. et al., Protein Science, 6, 1682-1693 (1997).

134. Johnson R.J., Lin S.R. \& Raines R.T., Protein Science, 16, 1609-1616 (2007).

135. Eberhardt E.S. et al., Protein Science, 5, 1697-1703 (1996).

136. Schultz D.A., Baldwin RL, Protein Science, 1, 910-916 (1992).

137. Klink T.A. \& Raines R.T., J. Biol. Chem., 275, 17463-17467 (2000).

138. Schultz L.W. et al., Protein Science, 7, 1620-1625 (1998). 
139. Di Nardo A.A., Larson S.M. \& Davison A.R., J. Mol. Biol., 333, 641-655 (2003).

140. Maxwell K.L. \& Davison A.R., Biochemistry, 37, 161721-16182 (1998).

141. Cobos E.S. et al., J. Mol. Biol., 328, 221-233 (2003).

142. Varela L. et al., FEBS Letters, 583, 801-806 (2009).

143. Pantoliano M.W. et al., Biochemistry, 26, 2077-2082 (1987).

144. Pantoliano M.W. et al., Biochemistry, 28, 7205-7213 (1989).

145. Bryan P.N. et al., Proteins, 1, 326-334 (1986).

146. Zhang N. et al., Protein Eng., 16, 599-605 (2003).

147. Kelley R.F., Cleary S., Biochemistry, 28, 4047-4054 (1989).

148. Ahmed S.A. et al., Biochem. Biophys. Res. Comm., 151, 672-678 (1988).

149. Lim W.K., Brouillette C. \& Hardman J.K., Arch. Biochem. Biophys., 292, 34-41 (1992).

150. Hiraga K. \& Yutani K., Protein Eng., 9, 425-431 (1996).

151. Hiraga K. \& Yutani K., Eur. J. Biochem., 240, 63-70 (1996).

152. Yutani K. et al., Proteins, 9, 90-98 (1991).

153. Matthews C.R. et al., Biochemistry, 19, 1290-1293 (1980).

154. Marmorino JL, Pielak GJ, Biochemistry, 34, 3140-3143 (1995).

155. Pielak G.J. et al., Biochemistry, 34, 3268-3276 (1995).

156. Betz S.F. \& Pielak G.J., Biochemistry, 31, 12337-12344 (1992).

157. Hickey D.R. et al., J. Biol. Chem., 266, 11686-11694 (1991).

158. Hermann L.M. \& Bowler B.E., Protein Science, 6, 657-665 (1997).

159. Fetrow J.S. et al., Biochemistry, 37, 2477-2487 (1998).

160. Liggins J.R. et al., Protein Science, 8, 2645-2654 (1999).

161. Lett C.M. et al., Biochim. Biophys. Acta, 1432, 40-48 (1999).

162. Linske-O'Connell L.I., Sherman F. \& McLendon G., Biochemistry, 34, 7094-7102 (1995).

163. McGee W.A. et al., Biochemistry, 35, 1995-2007 (1996).

164. Tang Y. et al., J. Mol. Biol., 355, 1066-1077 (2006).

165. Frank B.S. et al., Protein Science, 11, 680-687 (2002).

166. Kubelka J., Eaton W.A. \& Hofrichter J., J. Mol. Biol., 329, 625-630 (2003).

167. Ginsburg A. et al., Protein Science, 9, 1085-1094 (2000).

168. Tanaka M. et al., Biochemistry, 45, 10351-10358 (2006).

169. Gorshkova I.N. et al., Biochemistry, 41, 10529-10539 (2002). 
170. Ruiz-Sanz J. et al., Biochemistry, 34, 1695-1701 (1995).

171. Jackson S.E. et al., Biochemistry, 32, 11259-11269 (1993).

172. de Prat Gay G., Johnson C.M. \& Fersht A.R., Protein Eng., 7, 103-108 (1994).

173. elMasry N.F. \& Fersht A.R., Protein Eng., 7, 777-782 (1994).

174. Manna S.K. \& Mazumdar S., Biochemistry, 45, 12715-12722 (2006).

175. Dolla A. et al., Biochemistry, 38, 33-41 (1999).

176. Cho J.H. et al., J. Mol. Biol., 338, 827-827 (2004).

177. Luisi D.L. et al., Biochemistry, 42, 7050-7060 (2003).

178. Iwagami S.G. et al., Protein Science, 4, 2562-2572 (1995).

179. Matsumara M., Becktel W.J. \& Matthews B.W., Nature, 334, 406-410 (1988).

180. Ladbury J.E., Hu C.Q. \& Sturtevant J.M., Biochemistry, 31, 10699-10702 (1992).

181. Becktel W.J. \& Schellman J.A., Biopolymers, 26, 1859-1877 (1987).

182. Shoichet B.KK et al., Proc. Natl. Acad. Sci. USA, 92, 452-456 (1995).

183. Daopin S. et al., J. Mol. Biol., 221, 873-887 (1991).

184. Poteete A.R. et al., Biochemistry, 30, 1425-1432 (1991).

185. Chen B.L. et al., Biochemistry, 31, 1464-1470 (1992).

186. Zhang X., Baase W.A. \& Matthews B.W., Biophys. Chem., 101, 43-56 (2002).

187. Zhang X. et al., Protein Eng., 8, 1017-1022 (1995).

188. Wetzel R. et al., Proc. Natl. Acad. Sci. USA, 85, 401-405 (1988).

189. Nicholson H. et al., J. Mol. Biol., 210, 181-193 (1989).

190. Daopin S. et al., Biochemistry, 30, 7142-7153 (1991).

191. Nicholson H. et al., Biopolymers, 32, 1431-1441 (1992).

192. Alber T. \& Matthews B.W., Methods Enzymol, 154, 511-533 (1992).

193. Cornish V.W. et al., Biochemistry, 33, 12022-12031 (1994).

194. Alber T. et al., Science, 239, 631-635 (1988).

195. Hawkes R., Grutter M.G. \& Schellman J., J. Mol. Biol., 175, 195-212 (1984).

196. Pjura P. et al., Proteins, 15, 401-412 (1993).

197. Nicholson H. et al., Biochemistry, 30, 9816-9828 (1991).

198. Daopin S. et al., Proteins, 15, 401-412 (1993).

199. Zhang X., Baase W.A. \& Matthews B.W., Protein Science, 1, 761-776 (1992).

200. Karpusas M. et al., Proc. Natl. Acad. Sci. USA, 86, 8237-8241 (1989). 
201. Elwell M.L. \& Schellman J.A., Biochim Biophys Acta, 494, 367-383 (1977).

202. Alber T. et al., Nature, 330, 41-46 (1987).

203. Kanaya S., Oobatake M. \& Liu Y., J. Biol. Chem., 27, 32729-32736 (1996).

204. Akasako A. et al., Biochemistry, 34, 8115-8122 (1995).

205. Haruki M. et al., J. Biol. Chem., 269, 26904-26911 (1994).

206. Akasako A. et al., J. Biol. Chem., 272, 18686-18693 (1997).

207. Kimura S.A. et al., Eur. J. Biochem., 206, 337-343 (1992).

208. Kimura S. et al., J. Biol. Chem., 267, 21535-21542 (1992).

209. Kimura S., Kanaya S. \& Nakamura H., J. Biol. Chem., 267, 22014-22017 (1992).

210. Kanaya S. et al., J Biotech, 28, 117-136 (1993).

211. Ishikawa K. et al., Biochemistry, 32, 6171-6178 (1993).

212. Haruki M. et al., Eur. J. Biochem., 220, 623-631 (1994).

213. Ishikawa K. et al., Biochemistry, 32, 7136-7142 (1993).

214. Bolon D.N. \& Mayo S.L., Biochemistry, 40, 10047-10053 (2001).

215. Chakrabarti A. et al., Protein Science, 8, 2455-2459 (1999).

216. Ladbury J.E. et al., Biochemistry, 34, 2148-2152 (1995).

217. Prajapati R.S et al., Proteins, 53, 863-871 (2003).

218. Witarto A.B. \& Sode K., Protein Eng., 14, 891-896 (2001).

219. Takahashi Y. et al., Biochemestry, 45, 11005-11011 (2006).

220. Hasegawa J. et al., J. Biol. Chem., 274, 37533-37537 (1999).

221. Uchiyama S. et al., Protein Eng, 15, 455-461 (2002).

222. Santos J. et al., Biophysical Journal, 93, 1707-1718 (2007).

223. Ellerby L.M. et al., Biochemestry, 29, 5797-5806 (1990).

224. Shi P. \& Kirsch J.F., Protein Science, 4,2063-2072 (1995).

225. Ohmura T. et al., Protein Science, 10, 313-320 (1995).

226. Shi P., Holland D.R. \& Kirsch J.K., Protein Science, 4, 2050-2062 (1995).

227. Masumoto K. et al., Protein Eng., 13, 691-695 (2000).

228. Villafranca J.E. et al., Biochemestry, 26, 2182-2189 (1987).

229. Gekko K. et al., J Biochem, 116, 34-41 (1994).

230. Castro M.J.M. \& Anderson S., Biochemistry, 35, 11435-11446 (1996).

231. Kim K.K. et al., Protein Science, 2, 588-596 (1993). 
232. Berndt K.D. et al., Biochemistry, 32, 4564-4570 (1993).

233. Krowarsch D. \& Otlewski J., Protein Science, 10, 715-724 (2001).

234. Roy S. et al., Biochim. Biophys .Acta, 1774, 975-984 (2007).

235. Honda Y. et al., Biochim. Biophys. Acta, 1429, 365-376 (1999).

236. Xie H. et al., J. Mol. Biol., 360, 157-167 (2006).

237. Heinz D.W. et al., J. Mol. Biol., 236, 869-886 (1994).

238. Guo J. et al., Biochemistry, 53, 2855-2863 (2014).

239. Decroos C. et al., ACS Chem. Biol. , 9, 2157-2164 (2014).

240. Behera R.K. et al., Biochemistry, 52, 1373-1384 (2013).

241. Lan D. et al., Int. J. Mol. Sci., 16, 7273-7288 (2015).

242. Shen T., Guo Z. \& Ji C., Acta Cryst., F70, 697-702 (2014).

243. Torpenholt S. et al., Comp. Struct. Biotech. J., 13, 256-264 (2015).

244. Bian F. et al., PLoS One, 10, e0121108 (2015).

245. Boone C.D. et al., FEBS, 282, 1445-1457 (2015).

246. Porter J., Collyer C.A. \& Ollis D.L., Protein J., 34, 82-89 (2015).

247. Roland B.P. et al., Biochem. Biophys. Acta, 1852, 61-69 (2015).

248. Verma S. et al., Biochem. Biophys. Acta, 1844, 1219-1230 (2014).

249. Dow B.A. et al., Arch. Biochem. Biophys. , 550, 20-27 (2014).

250. Tian J. et al., PLoS Comp. Biol., 11, e1004207 (2015).

251. Floor R.J. et al., Chem. Bio. Chem., 15, 1660-1672 (2014).

252. Daudé D. et al., Protein Science, 22, 1754-1765 (2013).

253. Predki P.F. et al., Nature Struc. Biol., 3, 54-57 (1996).

254. Cha H.J. et al., Mol. Cells, 36, 39-46 (2013).

255. Narasimhan D. et al., Proteins, 23, 537-547 (2010).

256. Ahmad S. \& Madhusudhana R., Protein Science, 18, 1183-1196 (2009).

257. Grinberg A.V. \& Bernhardt R., Arch. Biochem. Biophys., 396, 25-34 (2001).

258. Uhlmann H, Bernhardt R, J. Biol. Chem., 270, 29959-29966 (1995).

259. De Serrano V.S. \& Castellino F.J., Biochemistry, 33, 3509-3514 (1994).

260. Chang Y., Zajiceck J. \& Castellino F.J., Biochemistry, 36, 7652-7663 (1995).

261. De Serrano V.S. \& Castellino F.J., Biochemistry, 31, 3326-33335 (1992).

262. Vercillo N.C. et al., Protein Science, 16, 362-368 (1992). 
bioRxiv preprint doi: https://doi.org/10.1101/036301; this version posted January 10, 2016. The copyright holder for this preprint (which was not certified by peer review) is the author/funder. All rights reserved. No reuse allowed without permission. 